\title{
ÁREAS VERDES URBANAS DE JUIZ DE FORA (MG): CONSERVAÇÃO ATRAVÉS DE USUÁRIOS?
}

\author{
Bruno Esteves Conde ${ }^{1}$ \\ Gabriel Hiotti Lino de Souza ${ }^{2}$ \\ Andrea Esteves Martins ${ }^{3}$ \\ Aline Moreira de Siqueira ${ }^{4}$ \\ Amanda Surerus Fonseca ${ }^{5}$
}

Resumo: O objetivo do presente estudo foi avaliar através de entrevistas realizadas com os usuários das principais áreas verdes da cidade de Juiz de Fora, MG, se estes contribuem para conservação e se tomam atitudes relacionadas a conservação e proteção das referidas áreas. Para tal utilizou-se da aplicação de formulários semiestruturados. Desta forma constatou-se que os mencionados usuários se interessam em zelar pelas áreas verdes destes espaços, mas não detém informações necessárias para conserva-los. Além disso, estes usuários não estão satisfeitos com a manutenção dada pela administração destas áreas. Sugere-se para a administração pública, o desenvolvimento de projetos de Educação Ambiental, a inserção de agentes de fiscalização e de informação sobre conservação e a promoção de eventos locais como palestras e outros.

Palavras- Chave: Educação Ambiental; Meio Ambiente; Qualidade de Vida.

\footnotetext{
1 Universidade Federal de Juiz de Fora - Instituto de Ciências Biológicas - Departamento de Botânica. E-mail: bcondebio@hotmail.com.

${ }^{2}$ Centro de Engenharias Doctum - Departamento de Engenharia Ambiental. E-mail: hiottiengenharia@outlook.com.

3 Universidade Federal de Juiz de Fora - Instituto de Ciências Biológicas - Departamento de Botânica. E-mail: aembiol@hotmail.com.

${ }^{4}$ Universidade Federal de Juiz de Fora - Instituto de Ciências Biológicas - Departamento de Botânica. E-mail: alinemds1@yahoo.com.br.

${ }^{5}$ Centro de Ensino Superior de Juiz de Fora - Faculdade de Ciências Biológicas - Campus Arnaldo Janssen. E-mail: mandinhasurerus@gmail.com.
}

Revbea, São Paulo, V. 10, № 4: 32-39, 2015. 


\section{Introdução}

Atualmente tem-se observado que o crescimento desordenado das cidades, acaba por interferir na configuração das paisagens urbanas, mostrando sérias consequências com relação à perda de referenciais, além do empobrecimento cultural e social (COELHO, 2000). Tais fatores desencadeiam na diminuição da qualidade de vida das populações humanas dos centros urbanos (CONDE et al., 2014). Neste sentido torna-se essencial para as cidades, a manutenção de suas áreas verdes, tais como parques, praças, jardins, canteiros e demais locais que possam apresentar alguma biodiversidade (BOVO; AMORIM, 2011).

Essas áreas são apontadas como indicadores de qualidade de vida (NUCCl, 2008), já que podem proporcionar aos seus usuários um espaço para a realização de diversas atividades físicas ao ar livre (CARVALHO; GONÇALVES, 2008), como caminhar, correr, pedalar além de interação com o meio natural, que é considerada por Lachowycz e Jones (2012) uma espécie de terapia que pode promover a diminuição do stress e contribuir para o bem estar físico e psicológico.

Segundo Marinho (2003), pessoas que costumam frequentar estes espaços, podem contribuir para conservação dos mesmos, sendo suas opiniões essenciais para subsidiar a manutenção e o planejamento urbano.

Neste sentido, o objetivo do presente trabalho, foi avaliar entre os usuários das principais áreas verdes da cidade de Juiz de Fora/MG, quais são as atitudes tomadas por eles que possam contribuir para a conservação destas, avaliando também a disseminação da Educação Ambiental com base na opinião destes usuários sobre o estado de conservação destes espaços.

\section{Material e Métodos}

\section{Área amostral} de Fora, MG:

O estudo foi realizado em quatro áreas verdes da cidade de Juiz

1) O campus da Universidade Federal de Juiz de Fora;

2) A Praça do Bom Pastor;

3) Os Jardins do Museu Mariano Procópio;

4) O Parque Halfeld (Figura 1).

Essas áreas foram escolhidas utilizando o critério de maior popularidade entre os usuários. São regiões conhecidas como as principais áreas verdes públicas da cidade de Juiz de Fora. 

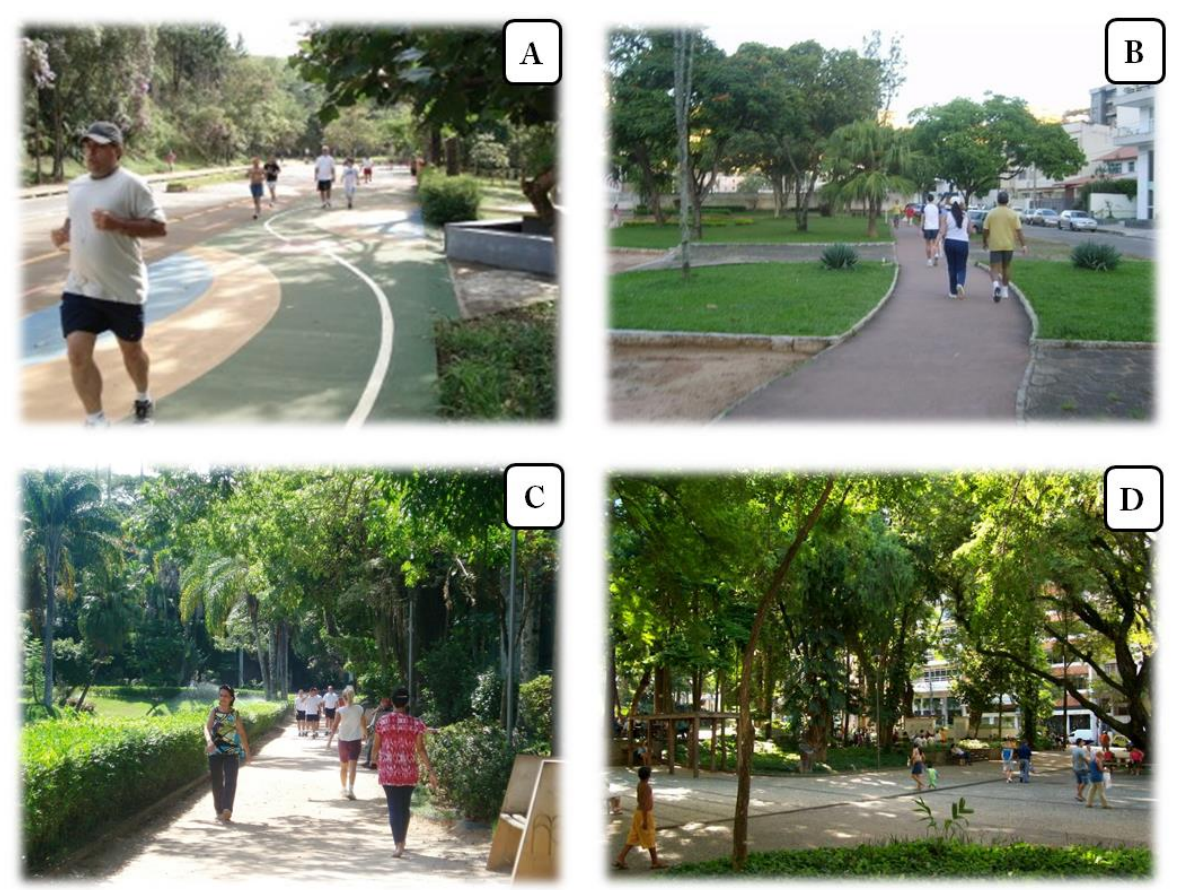

Figura 1: Áreas verdes na cidade de Juiz de Fora, onde é comum a realização de práticas de lazer e atividades físicas; A: Campus da Universidade Federal de Juiz de Fora, B: Praça do Bom Pastor, C: Museu Mariano Procópio, D: Parque Halfeld.

\section{Seleção amostral}

Para a quantificação do número de participantes que deveriam ser envolvidos na pesquisa, utilizou-se o método de amostragem intencional com base em Skrabe e Medina (2009). Através dessa metodologia foram selecionados os entrevistados que realizavam alguma prática de atividade física ou práticas de lazer ao longo de uma semana e que se auto consideravam usuários dessas áreas. Foram excluídos da pesquisa pessoas com idade inferior aos 18 anos.

\section{Consentimento dos participantes}

Antes da realização das entrevistas, os participantes escolhidos foram solicitados a assinarem um termo de consentimento em que concordavam em participar da presente pesquisa.

\section{Coleta de dados}

Realizou-se entrevistas com preenchimento de formulários semi estruturados (ALBUQUERQUE; LUCENA, 2004), com perguntas como:

1) Idade; 2) Há quanto tempo utiliza a área; 3) Quais atividades realizam nas áreas; 4) Quais as motivações para a utilização dos espaços; 5) Se tomam 
alguma atitude para conservação dos locais e quais são estas; 6) Se disseminam alguma ideia para conservação dos locais e quais; 7) Se já detectaram em outros usuários ações negativas e quais são; 8) Se acham que a área frequentada é bem conservada pela administração pública; 09) $O$ que acham que possa ser feito para a melhoria destas áreas.

\section{Resultados e discussões}

Foram selecionados 223 participantes, dos quais 98 eram homens e 125 mulheres. A idade média destes participantes foi de 36 anos e o tempo médio que frequentavam estas áreas é de três anos e seis meses. Tais dados demonstram que estes usuários utilizam os espaços por um tempo consideravelmente longo, as tornando alvos em ou agentes para a promoção conservação das mesmas.

Quanto às atividades realizadas nas áreas, destaca-se a corrida, com 105 pessoas, seguido de outras seis práticas esportivas e de lazer (Figura 2).

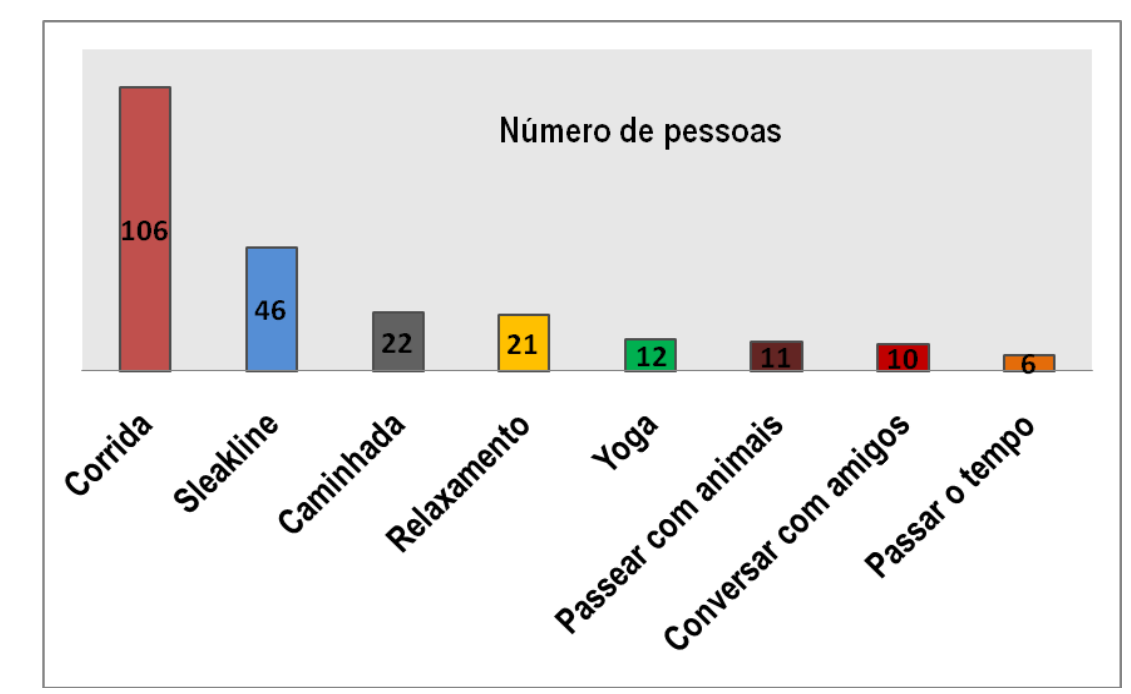

Figura 2: Atividades realizadas nas áreas estudadas e o número de citação de cada uma delas.

De acordo com Truccolo et al. (2008), a corrida é uma das modalidades esportivas que mais vêm aumentando entre os praticantes amadores de atividades físicas. Desta forma é considerada como sendo uma das atividades mais motivacionais e estimulantes da atualidade.

As principais alegações quanto à motivação de se utilizar os espaços estudados foram: presença de ar puro (60 participantes), diminuição do estresse (54 participantes) e combate a ansiedade (53 participantes) (Figura 3). 


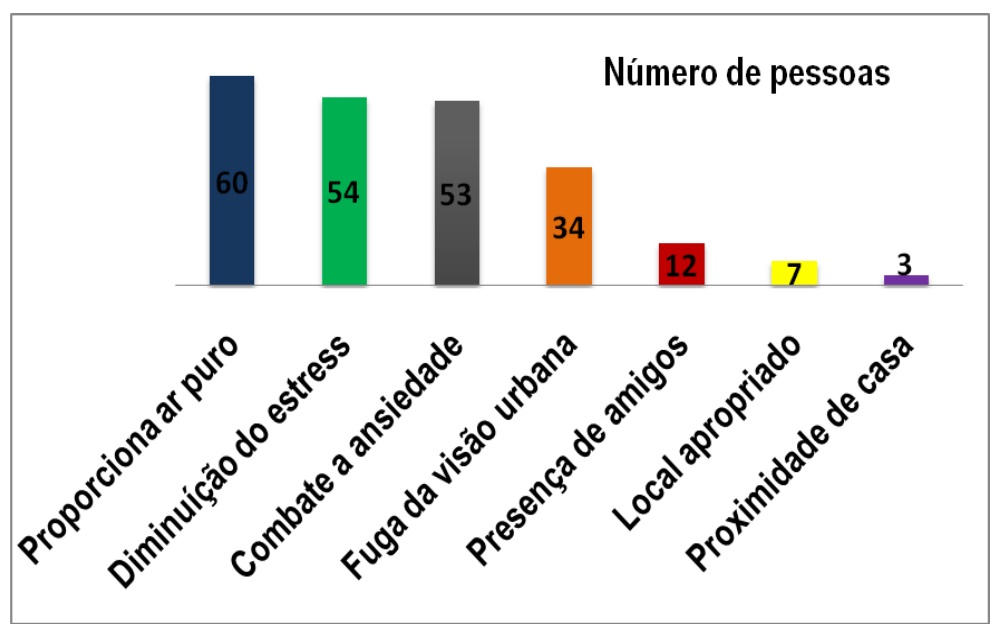

Figura 3: Alegações dos participantes para a utilização dos espaços.

Corroborando com os resultados obtidos por Brun et al., (2007), estes espaços são considerados por seus usuários como sendo filtros de poluição do ar e fornecedores de ar puro. Santana (2007) considera estes espaços, como sendo capazes de promover saúde e a qualidade de vida, proporcionando bem estar físico e psíquico.

A maioria (162 participantes) alegou ter tomado atitudes para contribuir com a conservação dos espaços utilizados, sendo a principal atitude alegada, 0 recolhimento de lixo (76 participantes) (Figura 4).

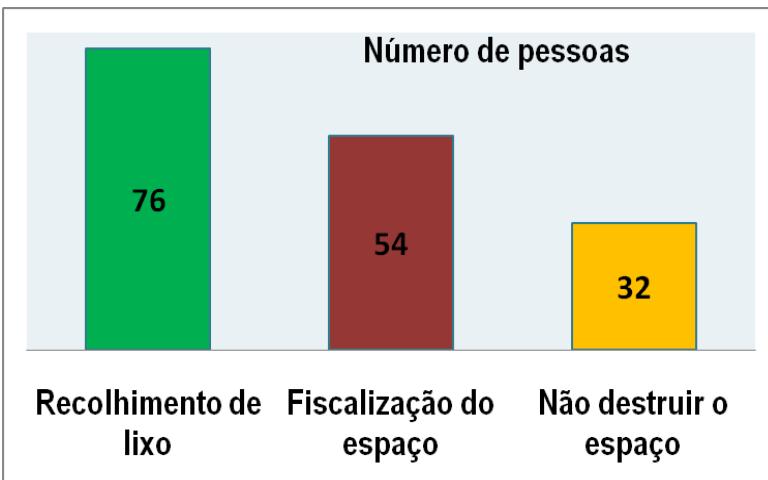

Figura 4: Atitudes alegadas como contribuição para a conservação dos espaços utilizados.

Estes resultados demonstram que os usuários destas áreas se esforçam para contribuir para a conservação destas, ainda que estes dados possam demonstrar também que o descarte de lixo fora dos locais apropriados (lixeiras) seja muito frequente, e assim sendo alvos de trabalhos que envolvam a Educação Ambiental. 
Quando se perguntou aos entrevistados se estes disseminam ideias para promover a conservação das áreas, 25 responderam positivamente. Tendo sido alegado por 19 destes que conversam informalmente com outros usuários da área sobre o descarte adequado do lixo. Tais dados demonstram que a questão dos descartes inadequados do lixo no local é tida pelos entrevistados como sendo o principal problema nestas áreas, e que iniciativas no âmbito da Educação Ambiental nestes locais poderiam viabilizar a minimização deste tipo de problema e de outros mais, já que não se pode acusar a falta de estrutura local como justificativa para o descarte indevido deste lixo. Nas áreas existem lixeiras visíveis e a limpeza pública foi observada diariamente no período em que se realizou a etapa de campo do presente trabalho.

Também foi possível perceber que a maioria dos entrevistados (187), acha que estas áreas são malconservadas, faltando iniciativas conjuntas entre usuários e administração pública. As principais alegações quanto a tal fato foram: bancos e calçadas quebradas com 103 citações, sendo apontado como principais responsáveis (83 citações) o vandalismo, e falta de poda e controle de cupim das árvores locais (69 citações) (Figura 5).

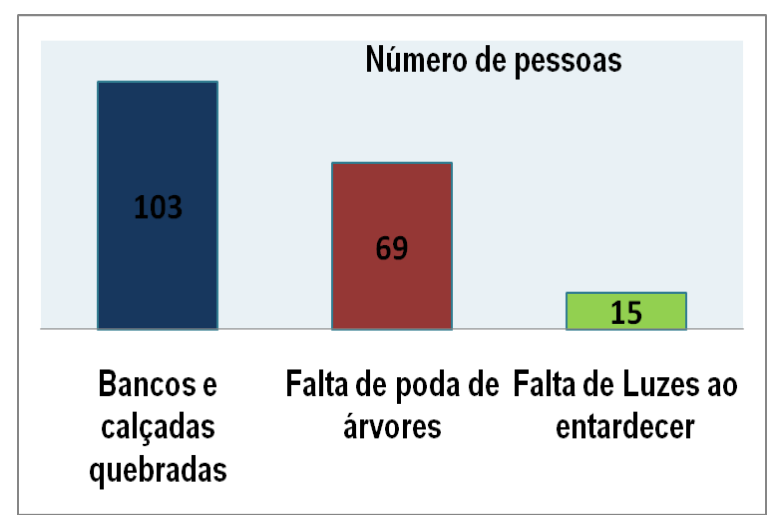

Figura 5: Alegações dos participantes, quanto à falta de manutenção das áreas utilizadas.

Tais resultados demonstram que na opinião dos usuários destas áreas falta atenção da administração pública para com estas áreas, no entanto o principal problema o vandalismo, não pode ser justificado pela falta de atenção da administração pública, mas sim, uma má conduta de determinados usuários caracterizada como sendo falta de educação social e ambiental.

Quanto à detecção de ações negativas de outros usuários, (17) citaram ter visto algo relacionado. Entre estes, 12 citaram o descarte inadequado do lixo e 5 citaram as pichações que podem ser vistas nos locais, o que também é caracterizado como sendo um ato de vandalismo. Segundo Quadros (2007), a fiscalização destas áreas é a forma mais efetiva e rápida para inibir as más condutas da população. Para reforçar a ação é indispensável à instalação de placas informativas sobre leis municipais, em na cidade de Juiz de Fora, como sendo a lei 12.924, que prevê multas e punições a quem sujar e não zelar pela 
conservação destes espaços. Além disso, agentes de Educação Ambiental poderiam estabelecer uma nova dinâmica para a conservação e avaliação dos espaços verdes urbanos na cidade de Juiz de Fora, MG.

O poder público precisa estabelecer um melhor diálogo sobre a conservação do meio ambiente com a população. O que será possível através da implantação de iniciativas do âmbito da Educação Ambiental nos locais, com a melhor formação de cidadãos ambientalmente corretos, como está previsto pela lei da política nacional de 27 de abril de 1999 e número 9.795.

\section{Considerações Finais}

Conclui-se que os usuários das respectivas áreas verdes da cidade de Juiz de Fora preocupam com a manutenção e conservação destas áreas, e procuram zelar pela manutenção destes espaços.

Apontou-se o descarte de lixo inadequado como sendo a principal ação negativa diagnosticada nos locais.

Também foi possível concluir que os usuários não estão satisfeitos com a atenção e manutenção dada pela administração pública para com estas áreas.

Sugere-se aos administradores públicos responsáveis, o desenvolvimento de programas voltados para a Educação Ambiental, tais com inserção de banners ou placas com explicações sobre as possibilidades de atitudes para conservação dos espaços, a inserção de agentes permanentes de fiscalização, a inserção de agentes de Educação Ambiental nos locais e a promoção de eventos como palestras sobre a conservação do meio ambiente, direcionados para os usuários locais.

\section{Agradecimentos}

Aos participantes, pela colaboração, a administração do Campus da Universidade Federal de Juiz de Fora e do Museu Mariano Procópio.

\section{Referências}

ALBUQUERQUE, U.P.; LUCENA, R.F.P. Métodos e técnicas para a coleta de dados. In: ALBUQUERQUE. U.P.; LUCENA, R.F.P. (org.). Métodos e técnicas na pesquisa etnobotânica. Recife (PE): Livro Rápido/NUPEEA. 2004.

BOVO, M.C.; AMORIM, M.C.C.T. Análise dos aspectos paisagísticos e de infraestrutura de áreas verdes urbanas: o caso de algumas praças de Maringá (PR) Brasil. Revista de Geografia, Meio Ambiente e Ensino, v.2, pp. 83-95, 2011.

BRUN, F.G.K.; LINK, D.; BRUN, E.J. Revista da Sociedade Brasileira de Arborização Urbana, v.1, n.1, 2007. 
CARVALHO, A.M.; GONÇALVES, A. Espaços verdes de Bragança. Bragança: Câmara Municipal de Bragança. 2008.

COELHO, M.C.N. Impactos ambientais em áreas urbanas - teorias, conceitos e métodos de pesquisa. In: GUERRA, A JT; CUNHA, S. B. (Org.). Impactos Ambientais Urbanos no Brasil, São Paulo (SP): Bertrand Brasil. 2000.

CONDE, B.E.; ROGERIO, I.T.S.; SIQUEIRA, A.M. FERREIRA ,M.Q. CHEDIER, L.M.; PIMENTA D.S. Ethnopharmacology in the Vicinity of the Botanical Garden of the Federal University of Juiz de Fora, Brazil. Ethnobotany Research and Applications, v. 12, pp. 91-111, 2014.

LACHOWYCZ, K.; JONES, A. Towards a better understanding of the relationship between greenspace and health: Development of a theoretical framework, Landscape and Urban Planning, v.118, pp. 62-69. 2012.

MARINHO, A. Da aceleração ao pânico de não fazer nada: corpos aventureiros como possibilidades de resistência. In: MARINHO, A.; BRUHNS, H. (Org.). Turismo, Lazer e Natureza, São Paulo (SP): Manole, 2003.

$\mathrm{NUCCI}$, J.C. Qualidade Ambiental e Adensamento Urbano: um estudo de Ecologia e Planejamento da Paisagem aplicado ao distrito de Santa Cecília, Curitiba (PR): MSP, $2^{a}$ ed., 2003.

QUADROS, A. Sedução ambiental: iniciativas populares e cidadania, Monografia de Especialização, Universidade Federal de Santa Maria - RS. 2007.

SANTANA, P.; NOGUEIRA, H.; SANTOS, R. Melhorar a Saúde Amadora Intervindo no Ambiente Físico e Social. In: SANTANA. P. A Cidade e a Saúde. Coimbra: Edições Almedina, 2007.

SKRABE, E.S.; MEDINA, N.M. Um programa de educação como ferramenta para enfrentar o tráfico de animais no Rio Grande do Sul/RS através de um programa de gestão ambiental da fauna silvestre. Revista Eletrônica do Mestrado em Educação Ambiental, v. 23, pp. 413-439, 2009.

TRUCCOLO, A.B.; ANDREATTA, P.B.; FEIJO, E.A. Fatores motivacionais de adesão a grupos de corrida, Motriz: Revista de Educação Física, v. 14, pp. 108-114, 2008. 